\title{
Dukungan Keluarga dan Lama Dialisis Sebagai Faktor Berhubungan Dengan Kepatuhan Pembatasan Cairan Pasien Gagal Ginjal Kronik
}

\author{
Tiurmaida Simandalahia ${ }^{a}$, Siska Sakti ${ }^{a}$, Ropendi Pardede ${ }^{b}$ \\ aProgram Studi Ilmu Keperawatan \& Ners, STIKes Syedza Saintika, Jl. Prof. Dr. Hamka \\ No.228 Air Tawar Timur Padang - Sumatera Barat, 25132, Indonesia \\ ${ }^{b}$ Program Studi Ilmu Kesehatan Masyarakat \& Manajemen Informasi Kesehatan, STIKes \\ Syedza Saintika, Jl. Prof. Dr. Hamka No.228 Air Tawar Timur Padang - Sumatera Barat, \\ 25132, Indonesia \\ e-mail korespondensi: tiurmaidamandalahi@gmail.com
}

\begin{abstract}
Noncompliance with fluid restriction is a problem in patients undergoing hemodialysis. The impact suchs pulmonary edema increases the risk of cardiovascular disorders, and hypertension. This study aims to determine the relationship of family support and the length of dialysis with adherence to fluid restriction in patients with Chronic Renal Failure (CRF) in the RST. Reksodiwiryo Padang. This type of analytic descriptive research with cross-sectional design. Data collection was conducted in August 2018 in the RST hemodialysis unit room Dr. Reksowidiryo Padang. The population was all patients with $C R F$ who underwent hemodialysis therapy with an average visit of 42 patients. Sampling by means of the total population. Data were collected using questionnaires and documentation studies, processed computerically. Univariate analysis with frequency distribution and bivariate with chi-square test significance of 0.05 . The results showed that $76.2 \%$ were not adherent to limiting fluid, $52.4 \%$ did not get family support, $66.7 \%$ were in the old category of running dialysis. There was a significant relationship between family support $(p=0.030)$ and dialysis time $(p=0.001)$ with fluid restriction compliance. It was concluded that there was a relationship between family support and the length of dialysis with fluid restriction compliance. It is suggested to officers to include, educate, and motivate patients with their families regarding fluid restrictions, describe the impact, and give enthusiasm in carrying out dialysis therapy and provide alternatives that can be done for fluid replacement in controlling thirst.
\end{abstract}

Keywords: Chronic Kidney Failure, Compliance, Fluid Restriction, Family Support, Dialysis Duration

\begin{abstract}
Abstrak
Ketidakpatuhan dalam pembatasan cairan menjadi masalah pada pasien yang menjalani hemodialisis. Dampaknya terjadi oedema paru, meningkatkan resiko gangguan kardiovaskuler, dan hipertensi. Penelitian ini bertujuan untuk mengetahui hubungan dukungan keluarga dan lamanya dialisis dengan kepatuhan pembatasan cairan pada pasien Gagal Ginjal Kronik (GGK) di RST Dr. Reksodiwiryo Padang. Jenis penelitian deskriptif analitik dengan rancangan cross sectional. Pengumpulan data dilakukan bulan Agustus 2018 di ruangan unit hemodialisa RST Dr. Reksowidiryo Padang. Populasinya adalah seluruh pasien GGK yang menjalani terapi hemodialisis dengan rata-rata kunjungan sebanyak 42 pasien. Pengambilan sampel dengan cara total populasi. Data dikumpulkan menggunakan angket dan studi dokumentasi, diolah secara komputerisasi. Analisis secara univariat dengan distribusi frekuensi dan bivariat dengan uji chi square kemaknaan 0.05. Hasil didapatkan $76.2 \%$ tidak patuh dalam melakukan pembatasn cairan, 52.4\% kurang mendapatkan dukungan keluarga, 66,7\% berada pada kategori lama dalam menjalankan dialisis. Ada hubungan yang bermakna antara dukungan keluarga $(\mathrm{p}=0,030)$ dan lama dialisis $(\mathrm{p}=0,001)$ dengan kepatuhan pembatasan cairan. Disimpulkan ada hubungan dukungan keluarga dan lama dialisis dengan kepatuhan pembatasan cairan. Disarankan kepada petugas agar mengikutsertakan, mengedukasi, dan memotivasi pasien bersama keluarga terkait pembatasan cairan, memaparkan dampak, dan memberikan semangat dalam menjalankan terapi dialisis, serta memberikan alternatif yang dapat dilakukan untuk penggantian cairan dalam mengontrol rasa haus.
\end{abstract}

Tiurmaida Simandalahi, dkk., Dukungan Keluarga dan Lama,... 
Kata kunci: Gagal Ginjal Kronik, Kepatuhan, Pembatasan Cairan, Dukungan Keluarga, Lama Dialisis

\section{PENDAHULUAN}

Gagal Ginjal Kronik (GGK) adalah gangguan fungsi ginjal yang progresif dan tidak dapat pulih kembali, dimana tubuh tidak mampu memelihara metabolisme dan gagal memelihara keseimbangan cairan dan elektrolit yang berakibat pada peningkatan ureum (Black, 2014). Ginjal memiliki fungsi menyaring, membersihkan dan membuang kelebihan cairan dan sisa-sisa metabolisme dalam darah, membantu memproduksi sel-sel darah merah, memproduksi hormon yang mengatur dan melakukan kontrol atas tekanan darah, serta membantu menjaga tulang tetap kuat (Sherwood, 2010;YGDI, 2014).

Angka kejadian penyakit GGK di Amerika Serikat pada tahun 2014 diperkirakan lebih dari 650.000 kasus. Selain itu sekitar 6 juta hingga 20 juta individu diperkirakan mengalami penyakit GGK tahap awal. Data di Jepang tahun 2011 didapatkan sebanyak 167.000 penderita dan tahun 2014 meningkat lebih dari 200.000 kasus (Santoso, 2009). Indonesia, tahun 2013 sekitar 300.000 orang, yang menjalani terapi sebanyak 25.600 orang, dan sisanya tidak tertangani. Sementara itu yang memerlukan terapi pengganti berupa hemodialisis, peritoneal dialisis, dan transplantasi ginjal adalah 400 per satu juta penduduk. Dikalkulasikan dengan jumlah penduduk Indonesia yang sekitar 240 juta jiwa, maka jumlah pasien yang perlu terapi sekitar 96.000 (Word Kidney Day, 2013).

Data dari Riset Kesehatan Dasar (RISKESDAS) tahun 2013 GGK termasuk urutan ke 3 dari 10 besar penyakit kronik di Indonesia. Penyakit GGK di Indonesia mencapai 30,7 juta penduduk. Sumatra Barat memiliki data pasien gagal ginjal kronik yang cukup tinggi, berdasarkan data pencacatan dan pelaporan medical record seluruh rumah sakit se-Sumatera Barat tahun 2014, tercatat sebanyak 368 pasien gagal ginjal. Jumlah ini hanya berasal dari rumah sakit yang mempunyai unit hemodialisa saja, sehingga insidensi dan prevalensi pasien yang menderita gagal ginjal jauh lebih banyak dari jumlah tersebut (Ayuandira, 2014).

Hemodialisis dapat memperpanjang hidup tetapi tindakan ini tidak akan mengubah perjalanan alami penyakit yang mendasari dan juga tidak mengembalikan seluruh fungsi ginjal. Pasien tetap akan mengalami sejumlah komplikasi salah satunya pada kardiovaskular, dengan gejala kelebihan cairan. Kelebihan cairan ini secara tidak langsung akan menyebabkan oedem paru, berat badan klien juga akan mengalami peningkatan yang cukup tajam mencapai lebih dari berat badan normal $(0,5 \mathrm{~kg} / 24 \mathrm{jam})$ yang dianjurkan bagi klienyang menjalani terapi hemodialisis (Smeltzer \& Bare, 2009).

Dampak jika penderita tidak melakukan pembatasan cairan adalah jumlah cairan yang ada akan menumpuk di dalam tubuh sehingga mengakibatkan edema, yang selanjutnya meningkatkan resiko pada kardiovaskuler dan hipertensi (Barnet, 2008).

Ketidakpatuhan pasien ditemukan pada semua aspek akan tetapi ketidakpatuhan terhadap pembatasan intake cairan adalah aspek yang paling sulit dilakukan oleh sebagian besar pasien. Iacono (2008) menyatakan bahwa diantara semua manajemen yang harus dipatuhi dalam terapi hemodialisis, pembatasan cairan merupakan hal yang paling sulit untuk dilakukan dan membuat pasien stress serta depresi, terutama jika mereka mengkonsumsi obat-obatan yang membuat membran mukosa kering seperti diuretik, sehingga menyebabkan rasa haus dan pasien berusaha untuk minum. Dikatakan tidak terjadinya penumpukan cairan jika cairan yang dikonsumsi dalam 
satu hari sebanyak $500 \mathrm{ml}$ ditambah jumlah urin dalam satu hari (Smeltzer \& Bare, 2009).

Wulan, S.N \& Emaliyawati, E (2018) menyebutkan bahwa hanya $37,6 \%$ pasien yang menjalani terapi hemodialisa patuh dalam pembatasan asupan cairan. Kepatuhan dapat terjadi salah satunya disebabkan tidak mampu menahan rasa haus (Syamsiah, 2011). Ketidakpatuhan dalam terapi pembatasan cairan dapat merusak efektivitas terapi sehingga mengakibatkan progresivitas penyakit yang tidak terduga dan kemungkinan akan memperbesar terjadinya komplikasi. Oleh karena itu diperlukan kepatuhan terhadap intake cairan pada pasien hemodialisis (Price \& Wilson, 2009).

Beberapa faktor penyebab ketidakpatuhan pasien hemodialisis melakukan pembatasan cairan dipengaruhi oleh umur, jenis kelamin, tingkat pendidikan, lama menjalani hemodialisa dan dukungan keluarga (Kammerer et al, 2007).

Dukungan keluarga merupakan suatu kenyamanan, perhatian, penghargaan atau menolong orang dengan sikap menerima kondisinya (Muhlisin, 2012). Dukungan keluarga tersebut diperoleh dari individu maupun kelompok. Dukungan keluarga dapat menjadi faktor yang dapat berpengaruh dalam menentukan keyakinan dan nilai kesehatan individu serta menentukan program pengobatan yang akan diterima (Niven, 2012).

Penelitian Umayah, E (2016) tentang hubungan tingkat pendidikan, pengetahuan, dan dukungan keluarga dengan kepatuhan dalam pembatasan asupan cairan pada pasien gagal ginjal kronik yang menjalani hemodialisa rawat jalan di RSUD Kabupaten Sukoharjo, menunjukan bahwa dukungan keluarga dalam kategori baik sebanyak 58,06\% dan kepatuhan pembatasan cairan dalam kategori patuh sebanyak $54,84 \%$, dengan hasil uji statistik terdapat hubungan yang bermakna antara dukungan keluarga dengan kepatuhan pembatasan cairan pasien gagal ginjal kronik $(\mathrm{p}=0,047)$.

Lamanya menjalankan terapi hemodialisis merupakan faktor lain yang mempengaruhi kepatuhan pasien dalam melakukan pembatasan cairan (Kammerer et al, 2007). Periode sakit dapat mempengaruhi kepatuhan. Pengaruh sakit yang lama, belum lagi perubahan pola hidup yang kompleks serta komplikasi-komplikasi yang sering muncul sebagai dampak sakit yang lama mempengaruhi tidak hanya pada fisik, tapi juga emosional, psikologis dan sosial pasien. Hasil riset pada pasien hemodialisis memperlihatkan perbedaan kepatuhan pada pasien yang sakit kurang dari 1 tahun dengan yang lebih dari 1 tahun. Semakin lama menderita sakit, maka resiko terjadi penurunan tingkat kepatuhan semakin tinggi salah satunya adalah kepatuhan dalam pembatasan cairan (Kammerer et al, 2007).

Pasien GGK yang menjalani hemodialisis di RST berada pada tahap kronik akhir/ tahap $\mathrm{V}$ dengan nilai LFG $<15 \%$ dan jumlah rata-rata pasien 3 bulan terakhir adalah sebanyak 42 orang. Jumlah ini cukup tinggi lebih banyak dibandingkan dengankunjungan ke Rumah Sakit swasta lainnya.

Hasil wawancara dengan 7 orang pasien pada tanggal 20 Mei 2018 di ruangan hemodialisis RST. Reksodiwiryo Padang diperoleh informasi bahwa 2 orang pasien mengatakan telah menjalani terapi hemodialisis selama 6 bulan. Pasien mengatakan patuh terhadap pembatasan cairan karena ingin sembuh dan keluarga juga sering mengingatkan agar membatasi asupan cairan sesuai anjuran dokter. Kemudian 5 orang pasien lainnya mengatakan telah menjalani terapi hemodialisis selama 1,5 tahun. Pasien mengatakan telah berusaha menjalani terapi pembatasan cairan sesuai dengan anjuran dokter, dan keluarga juga sudah mengingatkan untuk membatasi cairan dan mematuhi program pembatasan cairan, namun hal yang sulit untuk 
dikontrol adalah rasa haus, sehingga pasien tetap minum untuk menghilangkan rasa haus.

Merujuk dari latarbelakang diatas maka dilakukan penelitian tentang Hubungan dukungan keluarga dan lamanya dialisis dengan kepatuhan pembatasan cairan pada pasien Gagal Ginjal Kronik (GGK) di RST Dr. Reksodiwiryo Padang.

\section{METODE PENELITIAN}

Jenis penelitian ini adalah deskriptif analitik dengan rancangan cross sectional. Populasi penelitian adalah seluruh pasien GGK yang menjalani terapi hemodialisis di RST Dr. Reksodiwiryo Padang dengan rata-rata kunjungan pasien sebanyak 42 orang. Pengambilan sampel dilakukan secara total populasi dengan kriteria inklusi responden yang menjalani terapi dialisis 2 $\mathrm{x}$ seminggu dan eksklusi pasien yang mengalami penurunan kesadaran. Pengumupulan data untuk variabel dukungan keluarga digunakan kuisioner berdasarkan teori Friedman dengan indikator: dukungan instrumental, informasi, penghargaan dan emosional. dan variabel lama dialisis dan kepatuhan pembatasan cairan dilakukan studi dokumentasi dengan menggunakan lembar observasi, dan timbangan berat badan. Data diolah secara komputerisasi dan dianalisis secara univariat untuk melihat distribusi frekuensi: dukungan keluarga dengan hasil ukur kurang Baik dan Baik menggunakan mean/median, lama dialisis dikategorikan lama $(\geq 1$ tahun) dan baru ( $<1$ Tahun), kepatuhan pembatasan cairan dibagi menjadi patuh (jika $<4 \%$ ) dan tidak patuh (jika $\geq 4 \%$ ) dan bivariat untuk melihat adanya hubungan dari variabel yang ada menggunakan uji chi square dengan derajat kepercayaan $95 \%(\alpha=0.05)$.

\section{HASIL DAN PEMBAHASAN}

Tabel 1. Karakteristik Responden, Kepatuhan Pembatasan Cairan, Dukungan Keluarga, dan Lama Dialisis

\begin{tabular}{clll}
\hline No & \multicolumn{1}{c}{ Variabel } & f & \multicolumn{1}{c}{$\%$} \\
\hline 1. & Umur & & \\
& $->40$ tahun & 35 & 83,3 \\
& $-\leq 40$ tahun & 7 & 16,7 \\
\hline 2. & Jenis Kelamin & & \\
& - Laki-laki & 23 & 54,8 \\
& $-\quad$ Perempuan & 19 & 45,2 \\
\hline 3. & Pendidikan & & \\
& - SD & 3 & 7,1 \\
& - SLTP & 4 & 9,5 \\
& - SLTA & 21 & 50.0 \\
& - PT & 14 & 33,3 \\
\hline
\end{tabular}

4. Kepatuhan

Pembatasan Cairan

- Tidak patuh $\quad 32 \quad 76,2$

- Patuh $10 \quad 23,8$

5. Dukungan Keluarga

- Kurang Baik $22 \quad 52,4$

- Baik $20 \quad 47,6$

6. Lama Dialisis

$\begin{array}{lll}\text { - } & \text { Lama } & 28 \\ \text { - } & 66.7\end{array}$

- Baru $14 \quad 33,3$

Berdasarkan tabel 1 didapatkan bahwa sebagian besar responden berumur $>40$ tahun $(83.3 \%)$, lebih dari separoh $(54.8 \%)$ adalah laki-laki dan paling banyak (50.0\%) berpendidikan SLTA. Sebagian besar $(76.2 \%)$ responden tidak patuh dalam melakukan pembatasan cairan, lebih separoh $(52.4 \%)$ responden mendapatkan dukungan keluarga yang kurang baik, dan lebih dari separoh $(66,7 \%)$ responden sudah lama melakukan dialisis. 
NERS: Jurnal Keperawatan, Volume 15, No. 1, Maret 2019, (Hal. 25-35)

Tabel 2. Hubungan Dukungan

Keluarga dan Lama Dialisis Dengan Kepatuhan Pembatasan Cairan

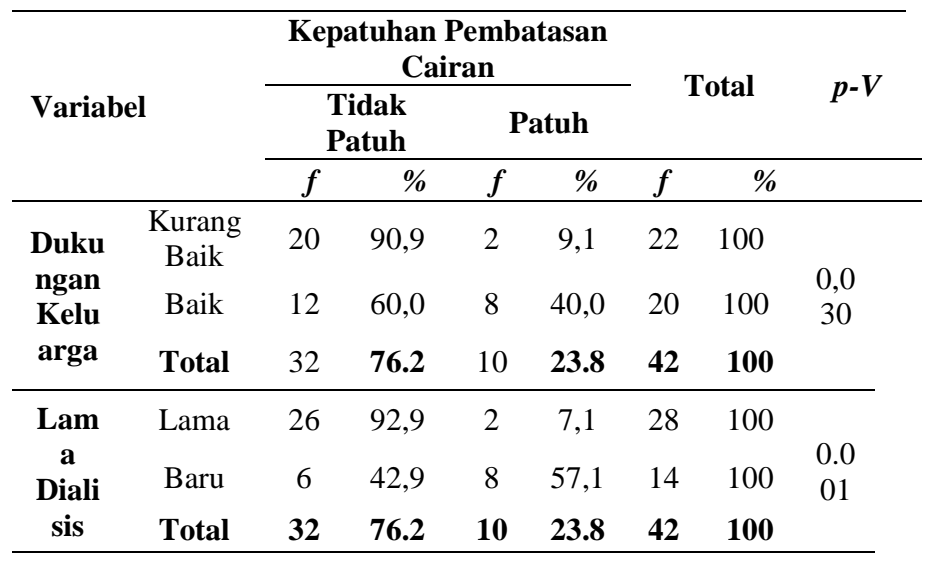

Berdasarkan tabel 2 didapatkan bahwa responden dengan dukungan keluarga yang kurang baik memiliki ketidakpatuhan dalam pembatasan cairan yaitu sebanyak 20 responden (90.9\%), dengan hasil uji statistik (chi square) diperoleh nilai $\mathrm{p}=0,030(\mathrm{p}<0,05)$, artinya Ha diterima dan Ho ditolak, terdapat hubungan yang bermakna antara dukungan keluarga dengan kepatuhan pembatasan cairan. Pasien yang sudah lama menjalankan dialisis memiliki ketidakpatuhan dalam pembatasan cairan yaitu sebanyak 26 orang (92.9\%), dengan hasil uji statistik nilai $\mathrm{p}=0,001(\mathrm{p}<0,05)$, artinya Ha diterima dan Ho ditolak, terdapat hubungan yang bermakna antaralama dialisis dengan kepatuhan pembatasan cairan di RST Dr. Reksodiwiryo Padang Tahun 2018.

\section{Kepatuhan Pembatasan Cairan}

Didapatkan sebagian besar responden tidak patuh dalam melakukan pembatasan cairan $(76.2 \%)$, sejalan dengan hasil penelitian Despitasari (2015) bahwa $73.0 \%$ pasien tidak patuh dalam pembatasan asupan cairan.

Karyati, S et al (2018) menyebutkan bahwa Kepatuhan pembatasan cairan pasien CKD sebagian besar kurang yaitu 49 (62,8\%) orang. Ketidakpatuhan menjadi masalah yang besar terutama pada pasien yang menjalani hemodialisis. Ketidakpatuhan dalam terapi pembatasan cairan dapat merusak efektivitas terapi sehingga mengakibatkan progresivitas penyakit yang tidak terduga dan kemungkinan akan memperbesar terjadinya komplikasi. Oleh karena itu diperlukan kepatuhan terhadap intake cairan pada pasien hemodialisis (Price \& Wilson, 2009).

Pembatasan cairan pada pasien GGK diukur berdasarkan Interdialytic Weight Gain (IDWG). IDWG diukur berdasarkan dry weight (berat badan kering) pasien dan juga dari pengukuran kondisi klinis pasien. Berat badan kering adalah berat badan tanpa kelebihan cairan yang terbentuk setelah tindakan hemodialisis atau berat terendah yang aman dicapai pasien setelah dilakukan dialisis (Kammerer et al, 2007).

Asumsi peneliti terkait hasil penelitian ini akan memberikan dampak yang negatif terhadap status kesehatan pasien karena dapat menyebabkan oedema dan komplikasi kardiovaskuler. Hal ini sesuai dengan yang dikemukakan oleh O'Callaghan (2009), bahwa apabila pasien tidak membatasi jumlah asupan cairan maka cairan akan menumpuk di dalam tubuh dan akan menimbulkan edema di sekitar tubuh seperti tangan, kaki dan muka serta penumpukan cairan yang terjadi di rongga perut yang disebut asites. Kondisi ini akan membuat tekanan darah meningkat dan memperberat kerja jantung.

Penumpukan cairan juga akan masuk ke paru-paru sehingga membuat pasien mengalami sesak nafas. Diperlukan adanya peran perawat yang menangani pasien untuk selalu patuh dalam pembatasan cairan sehingga bisa meminimalisir dampak negatif terhadap pasien. Perawat dapat menjelaskan dan mengingatkan kepada pasien bahwa cairan yang dibolehkan pada pasien hemodialisis adalah dengan menjumlahkan urin 24 jam ditambah 500-750 ml. Sesuai dengan teori yang dikemukakan O'Callaghan (2009) bahwa 
urin 24 jam ditambah $500-750 \mathrm{ml}$ adalah jumlah cairan yang dapat dikonsumsi pasien dan masih dapat ditoleransi oleh ginjal pasien.

Selain itu banyaknya pasien hemodialisis yang tidak patuh melakukan pembatasan cairan dapat dipengaruhi faktor umur, jenis kelamin, tingkat pendidikan. Berdasarkan hasil penelitian didapatkan sebagian besar responden berumur 40 tahun yaitu 35 orang (83.3\%), lebih dari separoh responden yaitu 23 orang $(54.8 \%)$ adalah laki - laki dan paling banyak responden yaitu 21 orang $(50.0 \%)$ berpendidikan SLTA.

Faktor lain yang yang menyebabkan pasien tidak patuh dalam pembatasan cairan adalah karena ketidakmampuan pasien menahan rasa haus dan keinginan untuk minum sangat tinggi sehingga pasien tidak mampu menahan haus.

\section{Dukungan Keluarga}

Hasil penelitian menunjukkan bahwa lebih separoh (52.4\%) pasien mendapatkan dukungan keluarga yang kurang baik. Hasil penelitian ini sejalan dengan penelitian Syamsiah (2011) bahwa $55.4 \%$ responden kurang mendapat dukungan keluarga.

Dukungan keluarga merupakan suatu kenyamanan, perhatian, penghargaan, atau menolong orang dengan sikap menerima kondisinya, dukungan keluarga tersebut diperoleh dari individu maupun kelompok (Muhlisin, 2012).

Niven (2012) menyatakan bahwa dukungan keluarga dapat menjadi faktor yang dapat berpengaruh dalam menentukan keyakinan dan nilai kesehatan individu serta menentukan program pengobatan yang akan diterima. Dalam memberikan dukungan kepada pasien keluarga membutuhkan kesabaran dan ketulusan karena tidak menutup kemungkinan timbulnya kecemasan seiring dengan lamanya waktu berobat pada pasien GGK yang umumnya dilaksanakan seumur hidup (Sunaryo, 2007).

Berdasarkan hal ini maka menurut asumsi peneliti terhadap penelitian ini adalah ditemukan cukup banyak pasien yang kurang mendapatkan dukungan keluarga, terlihat dari hasil analisis kuesioner, dimana didapatkan data bahwa keluarga kurang memberikan dukungan secara emosional yaitu $49 \%$ pasien menyatakan keluarga kurang memberi semangat terhadap pasien untuk tetap mengikuti program terapi hemodialisa dan pembatasan asupan cairan secara teratur, $48 \%$ pasien menyatakan keluarga tidak memberikan kenyamanan kepada pasiendalam melakukan program pembatasan asupan cairan. Secara informasional didapatkan sebanyak $48 \%$ pasien menyatakan keluarga tidak memberikan dukungan berupa tidak memberi mereka jadwal makan dan minum. Secara dimensi penilaian terlihat bahwa sebanyak $49 \%$ pasien menyatakan keluarga tidak meminta pendapat pasien tentang keberlanjutan menjalani program pembatasan cairan dan $45 \%$ pasien menyatakan keluarga tidak mengajak mereka berdiskusi tentang penyakit mereka dan perlunya pembatasan cairan.

Padahal dukungan ini sangat penting untuk memotivasi pasien dalam menjalani terapi sehingga akan memberikan keyakinan pada pasien dalam menjalani terapi. Dalam hal ini perlu adanya peran dari petugas kesehatan yang menangani pasien hemodialisis untuk memberikan program edukasi terhadap keluarga yang mendampingi pasien untuk selalu memberikan dukungan terhadap pasien sehingga dapat menambah keyakinan dan motiavasi pasien dalam menjalani pembatasan cairan.

\section{Lama Dialisis}

Hasil penelitian menunjukkan bahwa lebih dari separoh $(66,7 \%)$ pasien sudah lama melakukan dialisis $(\geq 1$ tahun). Hasil penelitian ini sejalan 
dengan penelitian yang dilakukan oleh Syamsiah (2011) bahwa $72.6 \%$ pasien menjalani lama nya HD pada kategori lama.

Hemodialisis merupakan suatu cara untuk mengeluarkan produk sisa metabolisme berupa larutan (ureum dan kreatinin) dan air yang ada pada darah melalui membran semi permeabel atau yang disebut dengan dialyzer (O'Callaghan, 2009). Tujuan dari hemodialisis adalah untuk mengambil zat-zat nitrogen yang merupakan toksik dari dalam darah, mempertahankan keseimbangan cairan, elektrolit dan asam basa, mengembalikan beberapa manifestasi kegagalan ginjal yang irreversibel (Black, 2014).

Jangka waktu yang lama dijalani pasien dalam terapi hemodialisis mengindikasikan kondisi tingkat kekronisan penyakit ginjal yang dialami pasien. Hemodialisis dilakukan dengan mengalirkan darah ke dalam suatu tabung ginjal buatan (dialiser) yang terdiri dari dua kompartemen yang terpisah. Darah pasien yang dipompa dan dialirkan ke kompartemen darah yang dibatasi oleh selaput semi permiabel buatan (artifisial) dengan kompartemen dialisat. Kompartemen dialisat dialiri cairan dialisis yang bebas dari pirogen, berisi larutan dengan komposisi elektrolit mirip serum normal dan tidak mengandung sisa metabolisme nitrogen (Sudoyo, 2010).

Lamanya terapi hemodialisis akan berdampak terhadap fisik dan psikologis pasien. Menurut Saputri (2013), hemodialisis biasanya dilakukan seumur hidup, dan menimbulkan dampak fisik dan psikologis pada pasien. Dampak fisik hemodialisis dapat menjadikan pasien lelah dan lemah sehingga mengakibatkan penurunan kemampuan dan keterbatasan dalam melakukan aktivitas sehari-hari. Selain dari dampak fisik, terapi hemodialisis ini juga berdampak pada psikologis pasien.

Berdasarkan hal ini maka menurut analisa peneliti terhadap penelitian ini adalah ditemukan cukup banyak pasien yang menjalani terapi hemodialisis dalam jangka waktu yang lama. Hal ini terlihat dari jangka waktu pasien dalam menjalani terapi $>1$ tahun. Lamanya terapi yang dijalani oleh pasien tergantung pada kondisi penyakit ginjal yang dialami pasien. Kondisi ini akan dapat mempengaruhi terhadap kondisi fisik dan psiologis pasien.

\section{Hubungan Dukungan Keluarga Dengan Kepatuhan Pembatasan Cairan}

Hasil penelitian menunjukkan bahwa proporsi pasien yang tidak patuh dalam pembatasan cairan lebih banyak terdapat pada pasien yang mempunyai dukungan keluarga kurang baik yaitu sebanyak 20 orang $(90.9 \%)$, dengan $p$-value $=0,030 \quad(\mathrm{p}<0,05)$, yang artinya ada hubungan yang bermakna antara dukungan keluarga dengan kepatuhan pembatasan cairandi RST Dr. Reksodiwiryo Padang Tahun 2018. Hasil penelitian ini sejalan dengan penelitian Yuliana (2015) bahwa ada hubungan dukungan keluarga dengan kepatuhan pembatasan cairan pada pasien $(\mathrm{p}=0.039)$.

Terbukti pada penelitian bahwa dukungan keluarga akan mempengaruhi kepatuhan pembatasan cairan pada pasien, karena dengan adanya dukungan keluarga yang baik maka pasien merasa mendapatkan perhatian dan akan memotivasi pasien untuk sembuh sehingga pasien akan patuh dalam menjalani pembatasan cairan. Sesuai dengan pendapat Niven (2012) bahwa dukungan keluarga dapat menjadi faktor yang berpengaruh dalam menentukan keyakinan dan nilai kesehatan individu serta menentukan program pengobatan yang akan diterima.

Pendapat lain disampaikan oleh Setiadi (2013) bahwa efek dari dukungan keluarga terhadap kesehatan dan kesejahteraan berfungsi bersamaan. Keberadaan dukungan keluarga yang adekuat terbukti berhubungan dengan 
menurunnya mortalitas, lebih mudah sembuh dari sakit, fungsi kognitif, fisik dan kesehatan emosi. Disamping itu, pengaruh positif dari dukungan keluarga adalah adanya penyesuaian terhadap kejadian dalam kehidupan yang penuh dengan stress.

Berdasarkan hal ini maka menurut analisa peneliti terhadap penelitian ini adalah terbukti dukungan keluarga mempengaruhi kepatuhan pasien dalam melakukan pembatasan cairan. Dimana terlihat bahwa jika pasien mendapatkan dukungan keluarga maka tingkat kepatuhan pasien dalam melakukan pembatasan terhadap cairan akan lebih tinggi dibandingkan dengan pasien yang kurang mendapatkan dukungan keluarga, dikarenakan pasien mendapatkan perhatian dari keluarga dan lebih terkontrol dalam melakukan pembatasan cairan sehingga tingkat kepatuhan pasien dalam pembatasan cairan juga akan lebih tinggi.

Agar pasien patuh dalam melakukan pembatasan cairan maka perlu adanya dukungan keluarga yang baik terhadap pasien. Dalam hal ini perlu adanya pemberian informasi kepada keluarga tentang pentingnya pembatasan cairan pada pasien sehingga keluarga dapat memberikan dukungan yang baik pada pasien dalam melakukan pembatasan cairan.

\section{Hubungan Lama Dialisis Dengan Kepatuhan Pembatasan Cairan}

Hasil

penelitian menunjukkanpasien yang tidak patuh dalam pembatasan cairan lebih banyak terdapat pada pasien yang sudah lama melakukan dialisis yaitu sebanyak 26 responden $(92.9 \%)$, dengan hasil uji statistik nilai $\mathrm{p}=0,001(\mathrm{p}<0,05)$, artinya ada hubungan yang bermakna antara lama dialisis dengan kepatuhan pembatasan cairan di RST Dr. Reksodiwiryo Padang Tahun 2018. Hasil ini sejalan dengan penelitian Despitasari (2015) bahwa ada hubungan lama dialisis dengan kepatuhan pembatasan cairan pada pasien $(\mathrm{p}=0.029)$.

Terbuktinya ada hubungan antara lama terapi dengan kepatuhan pembatasan cairan, dikarenakan lamanya terapi yang dijalani pasien menimbulkan kebosanan pada pasien sehingga pasien tidak dapat menahan rasa hausnya, dan mengkonsumsi cairan lebih dari jumlah yang dianjurkan (500-750 ml/ hari).

Menurut Saputri (2013) bahwa hemodialisis ini biasanya dilakukan seumur hidup. Hemodialisis dapat menimbulkan dampak fisik dan psikologis pada pasien. Dampak fisik hemodialisis dapat menjadikan pasien lelah dan lemah sehingga mengakibatkan penurunan kemampuan dan keterbatasan dalam melakukan aktivitas sehari-hari. Selain dari dampak fisik, terapi hemodialisis ini juga berdampak pada psikologis pasien.

Syamsiah (2011) menyatakan bahwa ketidakpatuhan dapat disebabkan salah satunya dari ketidakmampuan menahan rasa haus. Rasa haus merupakan masalah yang umum yang dirasakan pasien yang menjalani hemodialisis, dan penyebab ketidakpatuhan. Ketidakpatuhan dalam terapi pembatasan cairan dapat merusak efektivitas terapi sehingga mengakibatkan progresivitas penyakit yang tidak terduga dan kemungkinan akan memperbesar terjadinya komplikasi. Oleh karena itu diperlukan kepatuhan terhadap intake cairan pada pasien hemodialisis (Price \& Wilson, 2006).

Berdasarkan hal ini maka menurut analisa peneliti, lama terapi yang dijalani pasien menyebabkan kebosanan pada pasien dalam menjalani terapi, serta ketidakpastian untuk sembuh dan adanya efek rasa haus setelah menjalani terapi menyebabkan pasien tidak patuh dalam melakukan pembatasan cairan. Padahal kelebihan cairan dalam tubuh pasien akan berdampak terjadinya komplikasi pada pasien. Dalam hal ini perlu adanya dorongan motivasi terhadap pasien untuk 
melakukan pembatasan cairan sehingga pasien patuh dalam melakukan pembatasan terhadap cairan.

\section{SIMPULAN}

Dukungan keluarga dan lama dialisis memiliki hubungan signifikan dengan kepatuhan pembatasan cairan. Keberadaan dukungan keluarga yang adekuat terbukti berhubungan dengan menurunnya mortalitas, lebih mudah sembuh dari sakit, fungsi kognitif, fisik dan kesehatan emosi. Dukungan keluarga yang baik akan memberikan perhatian dan motivasi pada pasien untuk sembuh. Lama terapi yang dijalani pasien menyebabkan kebosanan pada pasien dalam menjalani terapi, serta ketidakpastian untuk sembuh dan adanya efek rasa haus setelah menjalani terapi menyebabkan pasien tidak patuh dalam melakukan pembatasan cairan.

\section{UCAPAN TERIMAKASIH}

Penulis mengucapkan terimakasih kepada Ketua Instalasi Pendididkan RS TK.III Dr. Reksodowiryo Padang dan Ketua Yayasan STIKes Syedza Saintika Padang yang telah berkenan memberikan izin untuk melaksanakan tri dharma perguruan tinggi terkhusus dalam penelitian ini serta mengizinkan dalam pengambilan data.

\section{DAFTAR PUSTAKA}

Ayuandira, Ega. (2014). Pengaruh dukungan sosial terhadap penerimaan diri pasien gagal ginjal dengan terapi hemodialisa di RSUP Dr M Djamil Padang. Jurnal Keperawatan Universitas Andalas.Diakses pada tanggal 14 Juni 2016 dari http://repository.unand.ac.id/

Baraz, S., Parvardeh, S., Mohammadi, E., \& Broumand, B. (2010). Dietary and fluid compliance: An educational intervension for patients having hemodialysis. Journal Of Advanced Nursing. 66 (1). $60-68$.

Barnet, T., Yoong, Li., Pinikahana, J., \& Yen, S. (2008). Fluid compliance among patients having hemodialysis: Can an educational programme make a difference?. Journal Of Advanced Nursing. Vol 61. 300 - 306.

Black, J M., \& Hawks, H. (2014). Keperawatan medikal bedah. (edisi 8. Buku 2).

Hidayati, Sri. (2012). Efektifitas konseling analisis transaksional tentang diet cairan terhadap penurunan Interdialytic Weight Gain (IDWG) Pasien gagal ginjal kronis yang menjalani hemodialisa di RS Daerah Kardinah Tegal. Tesis tidak diterbitkan. Jakarta: magister ilmu keperawatan Universitas Indonesia Depok.

Iacono, S. A., \& Da Vita Renal Health Care (2008). Medication Side Effects : Barriers to The Management of Fluid Intake. DaVita Renal Healthcare.http://onlinelibrary.wil ey.com/doi/10.1002/dat.20231/ful ldiakses tanggal 29 Maret 2018.

Jameson, J. L., \& Loscalzo, J. (2013). Harrison: Nefrologi dan gangguan asam basa. (Harrison's nephrology and acid-base disordes). (Brahm U. Pendit, Penerjemah). Jakarta : EGC.

Kammerer J., Garry G., Hartigan M., Carter B., Erlich L. (2007). Adherence in Patients On Dialysis: Strategies for Succes, Nephrology Nursing Journal: Sept-Okt 2007, Vol 34, No.5, 479-485. 
Karyati, S., Sukarmin., Listyaninsih, S. (2018). Hubungan dukungan keluarga dengan kepatuhan pembatasan cairan pada pasien ckd di rsud raa soewondo pati. The 8th University Research Colloquium 2018 Universitas Muhammadiyah Purwokerto. http://repository.urecol.org/index. $\mathrm{php} /$ proceeding/article/view/410/4 00

Mailani, F \& Andriani, R.F. (2017). Hubungan dukungan keluarga dengan kepatuhan diet pada pasien gagal ginjal kronik yang menjalani hemodialisis. Jurnal Endurance 2(3) October 2017 (416-423).

Mistiean, P. Thirst, Interdialytic weight gain, and thirst-interventions in hemodialysis patients: A literature review. Nephrology Nursing Journal. Vol. 28. No. 6.

Muhlisin, A. (2012). Keperawatan Keluarga. Yogyakarta: Gosyen.

Niven, N. (2012). Psikologi kesehatan pengantar untuk perawat \& profesional kesehatan lain (health psychology: An introduction for nurses and other health care professional). (Waluyo Agung, Penerjemah). (edisi 2). Jakarta : Salemba.

O'Callaghhan, C. (2009). At a glance sistem ginjal (the renal system at glance). (Yasmine Elizabeth, penerjemah). (edisi 2). Jakarta : Erlangga.

PERNEFRI (PerhimpunanNefrologi Indonesia). (2013). Indonesian Renal Registry. Bandung: Pernefri Indonesia.

PERNEFRI. (2011). Report of indonesia renal registry. $\left(4^{\text {th }}\right) 1-39$.
Potter, P.A \& Perry, A.G. (2005). Buku ajar fundamental keperawatan: konsep, proses, dan praktik (fundamental of nursing: Concepts, prosess, and practice). (Asih Yasmin, Penerjemah). (Edisi 4.Volume 1). Jakarta : EGC.

Price, S.A., \& Wilson, L.M. (2006). Patofisiologi konsep klinis proses-proses penyakit (pathophysioloy: Clinical concepts of disease processes). (Pendit Brahm U, Penerjemah). (Ed 6 vol 2). Jakarta: EGC.

Ratna, W.(2010). Hubungan dukungan keluarga dengan kecemasan pada pasien hemodilisis. Journal keperawatan. (Online) 1 (1), diakses dari www.google.com tanggal 17 September 2015.

Riskesdas. 2013.Riset kesehatan dasar, Indonesia.

Tersedia dari:http://www.depkes.go.id/reso urces/download/general/HasilRisk esdas2013.pdf.

Saputri, Veni. W. (2013). Faktor yang berhubungan dengan tingkat kecemasan pasien hemodialisa di ruangan Hemodialisis RSI Siti Rahmah Padang tahun 2013. Skripsi tidak diterbitkan. Padang : STIKes Mercubaktijaya.

Santoso, (2009). 60 Menit Menuju Ginjal Sehat. Jaring Pena: Surabaya

Sari, K. L. (2009). Faktor - faktor yang berhubungan dengan kepatuhan dalam pembatasan asupan cairan pada klien gagal ginjal kronik yang menjalani terapi hemodialisis diruang hemodialisa RSUP Fatmawati Jakarta 2009. Skripsi tidak diterbitkan. Jakarta: program studi ilmu keperawatan fakultas kedokteran dan ilmu 
NERS: Jurnal Keperawatan,Volume 15, No. 1, Maret 2019, (Hal. 25-35)

kesehatan universitas islam negeri syarifhidayatullah Jakarta.

Setiadi. (2008). Konsep dan proses keperawatan keluarga. (Ed 1). Yogyakarta.

Smeltzer, S.C \& Bare, B.G. (2009). Buku ajar keperawatan medikal bedah brunner \& suddarth). (Ed $8 \mathrm{Vol}$ 2). Jakarta : EGC.

Sudiharto. (2012). Asuhan keperawatan keluarga dengan pendekatan keperawatan transkultural. Jakarta : EGC.

Sudoyo, A. W., Setiyohadi, B., Alwi, L, Simadibrata, M., \& Setiati, S. (2010). Buku ajar ilmu penyakit dalam. (Ed 5). Jilid II. Jakarta : Pusat Penerbitan Ilmu Penyakit Dalam FKUI.

Sunaryo. (2007). Psikologi untuk keperawatan. Jakarta : EGC.

Syamsiah, N (2011), Faktor-faktor yang berhubungan dengan kepatuhan pasien ckd yang menjalani hemodialisa di RSP Audres Nawanantariksa Halim Perdana Kusuma Jakarta. Tesistidakditerbitkan.Jakarta: Magister keperawatanKekhususankeperawa tanmedicalbedahUniversitasIndon esia.

Tamanampo, Betti. (2009). Faktor-Faktor yang BerhubungandenganKepatuhanP enderitaGagalGinjalTahapAkhird alamMenjalankanHemodialisis di Unit

HemodialisaPelayananKesehatan St Carolus Tahun 2009. Skripsi FKM-Universitas Indonesia.
Dukungan Keluarga Dengan Kepatuhan Dalam Pembatasan Asupan Cairan Pada Pasien Gagal Ginjal Kronik yang Mejalanii Hemodialisa Rawat Jalan di RSUD Sukoharjo. Skripsi thesis, Universitas Muhammadiyah Surakarta. Diakses tanggal 8 Maret 2018. http://eprints.ums.ac.id/40506/

WHO.(2013). Adherence long-termtherapies.Evidence for action. Diakses tanggal 7 September 2015: http://www.emro.who.int/ncd/pub licity/adherence.

Wulan, S.N \& Emaliyawati, E. (2018). Kepatuhan Pembatasan Cairan dan Diet Rendah Garam (Natrium) pada Pasien GGK yang Menjalani Hemodialisa; Perspektif Health Belief Model. Faletehan Health Journa, 5 (3) (2018) 99-106. https://journal.lppm-stikesfa.ac.id

Yayasan Ginjal Diantrans Indonesia/ YGDI. (2008). Kontrol asupan cairan untuk pasien dialisis.

Umayah, Eti (2016) Hubungan Tingkat Pendidikan, Pengetahuan dan 